UDC 811.411.16(460)

vocesdehaketia.com

DOI https://doi.org/10.18485/fid.2017.7.ch25

\title{
DOES HAKETIA LEND ITSELF TO SERIOUS DISCUSSIONS?
}

Током последњих година дошло је до пораста интересовања за хакетију и наслеђе заједнице која говори овај варијетет. Овакав развој могао би бити повољан показатељ онога што може донети будућност.

Међутим, није много написано на хакетији, а савремени писци на овом дијалекту нису бројни. Један од фактора који доприносе томе јесте недостактак, до недавно, ортографског система. Ипак, критичнија је тенденција говорника хакетије да је посматрају као језик нижег регистра, чији је вокабулар неадекватан да изрази и напише суштинске мисли. Обично се сматра варијететом који је најпогоднији за уобичајене разговоре, а вицеви, афоризми, изрази и псовке појачавају овакво поимање. У овом чланку ја ћу истражити дијалекат и његове вишеструке аспекте на хакетији.

Кључне речи: хакетија, јеврејско-шпански, ладино, Мароко, жаргон.

\section{Nota de la autora}

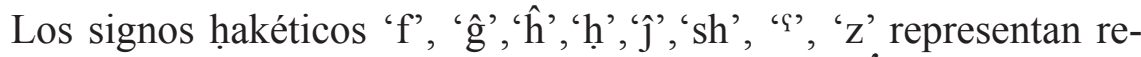

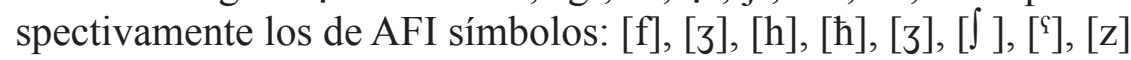

Al final está esplicación sobre unos particulares ḥakéticos, y aĵuntado está un glosario.

Haketía, un dialecto romance hablado prencipalmente en el norte de Marruecos, es el menos mentado de los vernáculos judeoespañoles. La fondina de la haketía - ḥakitía, haquetía, jaquitía, jaketía - Igual como el judeoespañol del oriente, es prencipalmente castellano medieval mescleado con vierbos de otros manaderos lingüísticos. En el pasado se hablabahaketíade talles y maneras en otros vezindarios del país y en Argelia; una de estas se topa todavía en Gibraltar. Este vernáculo se formó en Marruecos a lo largo de los 500 años dezde la espulsión. Ma 1860 marca el empesijo de la "rehispanización de la haketía", lo que rezultó en el trocamento de munchos vierbos de mizman kadmón por vierbos del español moderno, y 
en el caimento de la haketía en los ojos de sus hablantes. Ladino, como lo dize Sephiha, es la lengua calco del hebreo de las traducciones de los textos litúrgicos, sherkeada por todas las kehil.lót sefarditas del ${ }^{\varsigma}$ olam.

Ya en España, los sefardíes eran auzados de rosshear sus lenguas ibericás con vierbos hebreos y arameos, y tamién con unitos del árabe ibericó.

Y lo nota Benoliel (1977:5) que el poeta portugués del siglo XV ensembró en su poema Trovas de Louis Anrriquesvierbos del vocabulario sefardí, como: mazal, kadoz, sinoga, y aun defina - el guizado tradicional del almuerzo del Shabbat encade los judiós de Marruecos. Y del árabe ibéricó viene el palabraalhád- del vierbowahéd, significando uno -,la palabraque todos los sefardíes uzzan en vez de domingo, por no hazer la referencia a Jesús cristo. Y aun el vierbo hakético jbar/jbares, el que significa novedades, viene del árabe; en djudezmo se pronuncia jaber/jaberes. Ansina que, asigún los investigadores del tema, el lenguaje que los espulsados de España levaron con ellos a su nuevo vezindario en el norte de Africá fe el castellano medieval enjunto con palabras de los además dialectos ibericós de sus vezindarios - español por simplificación-y vierbos hebreos y arameos y unas pocas palabras del árabe. Este núcleo lingüístico, se evolucionó al vernáculo hakético. Y este mizmo vocabulario, menos los vierbos árabes, forma el vocabulario ladino, que se quedó cuazi sin trocarse en las traducciones de los libros reliĝiozzos por los rebbisím en España, y uzzado en escritos y hadrás emportantes.

Cuazi todos los sefardíes espulsados de España se afincaron emprimero alderredor del Mediterraneó y en los Balcanes. La mayoría de los que se fuyeron al norte de Africá, se pozzaron una vez más que otra en Marruecos y en el oeste de Argelia.Los sefardíes que instalaron sus moradas en el norte de Marruecos, en Turquía, Grecia, y en los Balcanes,cuidaron con cariño a su español medieval.Ma nonbalde que iban incorporando dabagar vierbos de su redondera nueva, y estos se integraron en la fondina española antigua. En Marruecos se adaptaron más vierbos hebreos y arameos, palabras del dialecto judeo-árabe marroquí y del portugués, y tamién un puñodel inglés y francés, lo que se evolucionó con tiempo en Marruecos a la haketía.

Ma, el judeoespañol de los espulsados que se fuyeron más pa el sur de Marruecos, se fe trocandose dabagar por el vocabulario judeomarroquí. 
En Debdú, Fez, Mequinez, Mogador y Wazzán por eshemplo, las cibdades que no son parte del norte hakético, se mantuvó una variante desferenciada durante años discués de la espulsión de 1492; los hablantes la llamaban por general español. Documentado está que en 1883 un grupo de vizitantes americanos a Wazzan se recibió con la saludación de venido wueno española, “Señores, buenos días...”.Edmundo De Amicis, autor italiano, vizitó Fez en la fondina del siglo XIX. Él se topó con mujeres judías, y lo notó: "Eran mujeres judías hermozzas,...y todas hablaban español..."Anque los sefardíes del centro y del sur de marruecos ya no hablan hoy en día judeoespañol, se topan hatta agüera en el vernáculo judeomarroquí esode dos mil palabras. La pronunciación me parece un poquito desferenciada; es máscerrada y aparecida al portugués. Por eshemplo: nigro, bandira, maístro.

La gramaticá hakética sigue por su mayor parte las reglas españolas,mamodelos antiguos se ven en las sintaxis y en la conjugación: 'Mira que vayas viniendo', 'estoy en que ese hará', 'tengoy encontrado'; en Benharroch (2004:680) se topa unalista grande. Caminí, caminates, caminimos, caminatis se conjugael vierbo caminar en el indicativo pretérito indefinido, demientras que en español es: caminé, caminaste, caminamos, caminasteis. Caminoy es la conjugación hakética de la primera persona en el indicativo presente; la española es camino.

El vocabulario adaptado se integró morfológicamente en haketía. Este grupo de vierbos,

sea su shoresh cual sea, se españolizó por medios de encoladas españolas tipicás al empesijo y al

final de la palabra. Por eshemploel vocablo paitán - cantor en hebreo - con el sufijo 'ear' camia

en paitnear, significando cantar en haketía.Baixo- portugués pa bajo,con el prefijo 'em', camia

en embasho, vocablo hakético por abajo.

Los sonidos de las consonantes españolas del zemán kadmón, las que ya no se topan en el castellano moderno, se prezervaron en haketía, y son parecidos al portugués. Los vierbos ḥakéticos ajuntar y cazza son las españolas juntar y casa. La[f] arcaica se conservó tamién una vez más que otra, igual se haddeanlos sonidos guturales del hebreo y árabe. 
El vocabulario español del zemán kadmón, el que es la base de ḥaketía, se quedó en su forma antigua: shabón y almadraque, au con unos camios: veluntad y escuraña, en vez de su forma de antes: voluntad y oscuridad. Munchos vierbos levan prefijos hakéticos tipicós: agustar, ensembrar, y no: gustar, sembrar. Y daca que hay un puño grande de palabras con entendido diferente del español moderno: pintado, quitado, significan en haketía: bello, divorciado. Otra uzansa es de jalfearlos 'v' y 'u' por 'b'. Por eso la ortografía y la pronunciación hakética de ciudad y deuda es: cibdad y debda.

Otros elementos hakéticos muy desferenciados del español, son la entonación y la acentuación tipicá: palabras españolas esdrújulas camiadas en agudas. La entonación muzical es tamién otra cozza por aseguir el modo de la habla rabinicá y árabe. Lo dize Bendayan de Bendelac (1990:17) "Además de ofrecer rasgos musicales del español, del árabe y del hebreo rabínico, la jaquetía tiene una tonada toda propia, una especie de pauta cantante con tonalidad e inflexiones que suben y bajan rítmicamente". La tonalidad que sube y abasha era dezde siempre una cozza hakética desferenciada, y se nota con clarezza. Ma, la acentuación rabinicá tipicá, en la que palabras esdrújulas camian en agudas, se topa más en las palabras del vocabulario hakético viejo, del de antes de 1860, que en los vierbos españoles que se ajuntaron a la haketía discués. Por eso polvorá y talamón, palabras hakéticas dezde siempre son agudas.Ma, periférico y vernáculo, palabras dezuzzadas antes de 1860, quedan esdrújulas. Lo que cuede significar, que las palabras modernas que reemplasaron las antiguas, ya no se integran morfológicamente en haketía.

Anque la comunidad hakética es mesjeada, se ve una diferencia nonadita entre una cibdad a otra: los tangerinos rosshean su haketía con más del francés, inglés, y del dialecto judeomarroquí. Y pamorde la influencia francezza, la 'ch' se pronuncia como en francés:[〕]. Las palabras adaptadasen la habla de Tetuán son por general del judeomarroquí namás, y esta habla es notada tamién por las eliziónes y las consonantes finales mudas de los vierbos. Por eshemplo 'los dedos' y 'Tatúan' se pronunciaran: 'lo_dedos' y 'Tetuá'.Y la haketía de Larache y Arzila es notada por elwuenque más grande de [f] inicialy vierbosportuguezzes 
El shoresh del nombre haketía es misteriozzo, y siguen todavía los dimes y diretes sobre cuál podría ser su manadero. Los leídos y escribidos prezentan unos penserios. Jose Benoliel, especialmente (1977:4) escribe que hạaketía salió de la palabra árabe haká, la que significa charlar au narar, y él aznea la posibilidad que ansina el vernáculo se nombró porlos judiós del sur de Marruecos cuando legaban al norte. Ma, otros, Isaac B. Benharroch y Joseph Toledano por eshemplo (2004:38) dizen que el vocablo haketía salió del nombre hebreo Is.ḥaq. Su diminutivo, Is.ḥaquito, se evolucionó a ḥaquito / hakito y por estensión aḥaquetía / haketía, za`ama‘la lengua de los ḥaquitos/ ḥakitos'.

Ma yo azneoy que sería una rarezza si la kehil.lá del norte de Marruecos, la que dezde siempore fe enfechizzada con su herencia y su judeoespañol, escoĝería bien escogiido un nombre árabe pa su vernáculo. Y más hay que parar mientesen que los sefardíes del sur y del centro de Marruecos no eran fetneados del nombre haketía, y no nombraron a su judeoespañol con este nombreMa, Bendayan de Bendelac y otros investigadores (1995: XXXIV) se coĝendela teoría de José Benoliel, y ansí vino a ser que el nombre haketía se afincó con la pluma y la obra de Benoliel, y haketía se escribe con ' $k$ ' y no con 'qu'.

La palabra haketía se enmentó emprimero en 1919, en el libro Los hebreos de Marruecos por Ortega (1919: 228). Y mirailo que en el tiempo de la guerra de Africá, en 1860, los soldados españoles hablaban de la lengua: “...castellano...con un acento particular...distinto del de todas nuestras provincias..." Eso del acento "particular" y raro, yase notó en este artículo eltrocamento de palabras esdrújulas en agudas.Ma daca que en mi cazza nuncua oí la palabrahaketía, y mizmo mi abuela la descansada no sabía que estamos hablando algo otro que español; mozotros llamimos a muestra lengua español ucán.

Sea cual sea el shoresh del nombre, la haketía es un vernáculo rico y sabrozzo que fe rossheandosecon munchos manaderos culturales y lingüísticos a lo largo de los años. En la haketía, con su modo pintoresco de hablar, su mizán melodiozzo tipicó, y su entonación que sube y abasha, están espresados la chispa, la riza, y la gracia - unos de los razgos de los judiós de Marruecos. La demanda retórica y repeticiones de vierbos del mizmo entendido se haze muncho pa dar pezzo a la habla. Por eshemplo, 
pa espresar algo malo, se dirá preto carbón, y pa espresar muncho frio se dirá frio agrís. ¿A qué te diré y qué te contaré?', no es una demanda, ma es un empesijo tipicóde habla. En vez de dizir por eshemplo: 'Ella me saludó, y yo tamién la saludí, pamorde que ella nuncua me hizo nada malo’ se dirá: 'Ella me saludó, ¿a wa no la saludaré yo tamién? ¿A qué es esto?, ¿algo malo me hizo ella?’ Los dimes y diretes diarios, llenos de cadenas de demandas que se segundan con otras demandas, son una uzansa hakética.

La riquezza lingüística se nota con el wuenque de dichos, espresiones, refranes, y sinónimos floridos, que luzzen cada hadrá. Y los refranes y espresiones, de ellos son pa enderechar y dar pezzo a los valores de la kehil.lá; de ellos pa la burla y el sarcazmo; y de ellos pa espresar cariño, etc. Lo siguiente es un eshemplo de los sinónimos y espresiones que forman parte de cada conversación:

- Amargo fiel. Feo/a como una noche de escuraña. Hermozza como la luna.

- El saber no ocupa lugar. ${ }^{\complement}$ Adlea la gotera, adobaras la cazza entera.

- En caminos de leche y miel. Durce lo vivas. Reyes te sirvan. Mi rey / reina; mi wueno.

- Baldiciones: Ida sin vuelta, camino sin mensajero. Candela en sus huesos.

La libertad lingüística juguetona de la haketía es característica a los vernáculos, escribe Solly Levy. (2008:21),palabras y silabas se entortan y se arrevolven con gusto. En los dorot ultimós, sabiendo tamién el español moderno, esto se haze con muncha creatividad y chispa:en vez de sentar, se dirá asentuyar, y pa describir un matrimonio empretecido se dirá Cazzapreto - un juego de las palabras cazzamento y preto.

Este espíritu juegueton no tiene lugar en ladino. Sephiha (1997:2930) y otrosdizen que la lengua de meldar fe siempre el ladino, común a toda la diasporá sefardí. "A fazerlo en ladino", y tamién "A ladinar", dizían los rebbisím en España cuando tradushían los escritos reloĝiozzos del hebreo al español. Los textos se tradushían palabra por palabra, ma asigún la sintaxis hebrea. La fraze hebrea con el entendido de "En estos días" de la Meguilá de Esther, fe tradushida al ladino: "En los días los estos". Vienen los investigadores y filólogos, y dizen que por eso tienef alta de clarezza. Ansina que el ladino, la lengua calco del hebreo, nuncua aprestó pa hablar. 
Y dizen ellos que ladino se topa namás en los escritos sagrados que se tradusheron antes, como la Hagadá de Pesah. Y lo notó Séphiha (1997:29) que el ladino es "hebreo con vestido español". Encade los sefardíes de Marruecos ladino significa las traducciones de los libros sagrados por los rebbisím en España.El vocabulario ladino es por su mayor parte el núcleo lingüístico que se levó de España, y como lo dize Sephiha (2002:330), es la fondina de todos los vernáculos judeoespañoles que se formaron discués de la expulsión. Él dize que el ladino y la variedad de las lenguas judeoespañolas son como "El águila de dos cabezas".

En haketía se habla, juega y reía, ma ende mal y ende negro, no se escribía, ni se escribe, muncho: de lo de antes, se topan unas notas privadas, refranes y padrones pala famía. Bentolila dize (2008:164) que cuando se escribía algo emportante, por los rebbisím au por la poca ĝente educada de ma ala, y aun cuando se hadreaba con estranjeros,se hazía con el vocabulario kadmón del español antiguo, lo que es el vocabulario de ladino.Y se hazía esfuerso de escribirlo derecho,y despejado de palabras estranjeras, en particular las del árabe. Los darushes pa las eznogas, los piyyutím, los dimes y diretes con otras kehil.lot sefarditas se hazían de esta manera.

En una nota de agradecimiento al pintor Delacroix, del año 1830, en Tanger, está escrito “...mos han hecho la gracia de bizitarmos día de domingo..." Anque escrita en estilo antiguo, la nota está despejada de vierbos árabes, y hatta que en vez dealhád, la que es uzzada encade todos los sefardíes, está escrito domingo.Otra cozza enteresante es el tiempo compuesto y la manera antigua de espresar las gracias. En haketía de día en día se diría, mos hizo el kabod y no "mos han hecho la gracia".

Nonbalde que es natural escribir en modo más derecho, como el Dio manda, que cuando se habla. Ma esto que vino a ser que en una entrevista que hizí y demandí sobre la vida de una mujer nacida en Larache en la fondina del siglo XIX, me disheron "pero si la abuela no hablaba haketía, la abuela hablaba ladino..." Esto, como cozzas iguales que se disheron por otros, mostra que el vocabulario hakético despejado del árabe, se veía más culto y elevado, y se refería tamién por algunos como ladino.

En haketía feronintegrandosen palabras emprestadas, y el vernáculo fe creciendo dabagar a lo largo de los años. Ma en 1860 la ḥeketía recibió un empushón lingüístico grande. Contodo y que las clases educadas de 
ma`ala, los rebbisím y los mercaderes de las cibdades costeras en particular, ya eran fetneados de la cultura y la lengua española moderna,cuazi todoslos otros vivían en un aizlamiento antes de 1860 .

Discués de ese año, las cozzas ya no avoltaron de ser como antes. Benharroch (2004:40-44) describe las razones poresta rehispanización, ampesando con la toma de Tetuán yla quedada de los españoles en la cibdad por eso de dos años. Los contactos con los que emigraron feras de Marruecos pa bushcar la vida, aumentaron a este proceso. Otras cozzas feron la prezencia de poderes europeas en Marruecos, y muncho pezzo en la rehispanización es debida a la criación de las escuelas de la Alianza Israelita Universal dezde 1862. Ma daca que el empushón ultimó en esta cadena de camios feron el protectorado español y francés dezde 1912.

Demientras que los sefardíes del norte de Marruecos descubrieron de nuevo la cultura y la lengua española moderna, las escuelas de la Alianza enjunto con el protectorado Francés tuvieron otros cabos en el centro y el sur de Marruecos. El vocabulario judeoespañol encade los sefardíes de la zona francezza, se trocó por el francés. Quedó una nonadita namás de vierbos judeoespañoles en su habla, las que Benharroch conta por unos dos mil vocablos españoles. (204: 607)

Esta evolución de la ḥaketía, notada ya en la fondina del siglo XIX, fe avansándose con ḥalḥalás en los años viñenes, como se vea lo largo del texto de las actas en Pimienta y Pimienta (2010), en las que el vocabulario fe españolizándose de una acta a otra. El vernáculo volvió a ser una mescla de español moderno y ḥeketía, o sea, una haketía españolizada, como lo dize Bendayan de Bendelac (1990:21). Es una uzansa demunchos hakakitos de halfear palabras entre español y haketía, sin consinter cual son cual.

Y daca que en munchas cazzas no se deshaba de hdrear en haketía. Los jovenés y la gente educada abandonaron a la haketía a favor del español y francés, junto con la adopción del vestimento flamengo. Se cuede dizir, que la haketía se puzzó en un guardijo, en la escuraña, leshos de los ojos y de los oídos. ¿A de que la valió y de que la aprestó su gracia y su dursor, si la hạketía se deshó en escondij̄o, en el rincón de las siete semanas?

Hatta más o menos el empesijo del siglo XIX, se escribía en la escritura solitreo, y por vezes en letras latinas. Ma no habían reglas, lo que era un negro mazzal que arrefolló la haketía. Por fin, un grupo de académicos, activistas, y 
escritores, encabesado por Yaakov Bentolila, asentaron cabesa pa arremediar esta situación quebrada, y se hizo un sistema de grafía pa la haketía.

Agüera, la kehil.lá judeomarroquí está desparpajada en todo el ${ }^{\mathrm{S}} \mathrm{O}$ lam. Ansina que la mayoríaestá qaileando leshos del manadero espiritual, emocional y cultural; leshos del pozzo geograficó endonde se wakfeaban las raíces. Ma, mirailo, que en los años ultimós se está alevantando un interésendiamantadoen la haketía. Anque muy pocos son los que escriben en haketía- no son muncho más que una mano de ellos -se mirauna actividad hakéticaferfleada.Palabras olvidadas y sonidos perdidos de la pronunciación hạakética deantes se están uzzando de nuevo. El futuro mos dirácómo se avansará y ande legará, y que será el cabo deesto. Ma, sea cual sea lo que vendrá, laḥaketíaes la lengua que toca la alma de sus hablantes con ternura; y siguesiendo la lengua de cariño.

\section{Unos particulares de la ḥaketía}

- El ceceo no existe en la haketía. La ' $z$ ' castellana se camia por 's'.

- Letras dobles indican una pronunciación acentuada (1.1, mm, ssh, zz,).

- Palabras de origen árabe (menos en hebreo) se distinguen por la ausencia de la 'u'después de la 'q'.

\section{Glosario}

a - intensificadora de lo que sigue, iniciadora para mover el discurso o la acción. abashó - abajó. ${ }^{\complement}$ adlear - arreglar.

Adonay - Dios.afincar - establecer.agrís - escarcha.Almadraque - colchón. aprestar - servir, ser útil.arrefollar -e stropear.au- o.aznear evaluar, pensar.baldición - maldición. [el] cabo - el camiar - cambiar. cazzamento - casamiento. cibdad - ciudad.consinter - prestar atención. cuazi - casi.cuede - puede.

darushes - sermones.dabagar - poco a poco; con tiempo.del'adaú - muy grande, estupendo. demanda - pregunta.derecho - correcto, justo. deshar- dejar.desparpajada - dispersa.despejar - libre de..., claro.dezmazzalado - alguien sin buena suerte. dezvaler - menospreciar.dizir - decir. dorot - generaciones.durce -dulce. empretecido - estropeado.empushón - 
empujón.encade - en casa de.enderechar - corregir.endiamantada- maravillosa.enmentar - mencionar.escuentra de - al contrario, contra de... eshemplo - ejemplo.eznoga - sinagoga (singa).ferflear - espabilar.fetnear - dar cuenta. flamanguerías - alardes de educación europea.flamengo - europeo. fondina - base, fondo, final.ḥaddean - cuidan. hadrá - habla, charla.ḥatta - hasta. jalfear - cambiar.jammear - pensar.kabod - respeto.kadosh- santo. kehil.lá - comunidad judía.legó - llegó. Legar - llegar.luzzen - s.e.c.: decoran.ma - pero.[de] mammasut - importante, con substancia. manadero - origen; fuente.mazzal - suerte.meldar - rezar.mentado - famoso.minhá oración de la tarde.nonada - cantidad chica, insignificante.nonbalde - con razón.nuncua - nunca. ${ }^{5}$ olam- mundo.pa -para.padrones - listas.pamorde que - por la razón de. penserio - pensamiento.por mal - lamentablemente. por vezes - a veces.qaileando - permaneciendo.quebrada - s.e.c.: estropeada.rosshear - salpicar, regar.

segunda - respuesta.sherkeada - compartida, común. shoresh - origen, la raíz.siguemos - seguimos.traduzer - traducir; tradusheron - tradujeron.trocar - cambiar , generalmente a lo peor.una vez más que otra - por general.uzansa - costumbre.vaydabber - asunto.vezindario - vecindario, región. wakfear - sostener.wuena - buena. wuenque - de: bueno que $=$ cantidad enorme.za'ama - como sí, es decir.zeman kadmón - tiempos antiguos.

(exp.) - Espreciones

${ }^{\varsigma}$ Addlea la gotera, adobaras la cazza entera -Remediar y pagar atención a los detalles pequeños, evita problemas grandes.

Asentar cabeza- Pensarlo lógicamente.

Contodo y - A pesar de...

Daca que - figurad; escuchad.

Dimes y diretes - negociaciones, intercambios de ideas, de vistas.

Ende mal y ende negro - por desgracia.

Filo por aguja - en detalles

Negro mazzal - Mala suerte.

Parar mientes - prestar atención, fijarse en 1 que está pasando.

Rincón de las siete semanas - un lugar triste y lúgubre.

Una mano-cinco. Por superstición el "cinco" se reemplaza con "una mano". 


\section{References:}

Alarcón, Pedro Antonio de. Diario de un Testigo de la Guerra de África. Madrid: Ediciones del Centro, 1859.

Albo Daniel. "The Education in the Jewish Community in Wazzan at the Beginning of the Twentieth century." 33-50. Brit, Summer 2011.

Alexander-Frizer, Tamar, y Bentolila Yaakov. La palabra en su hora es oro: El refrán judeo-español del Norte de Marruecos. Jerusalén: Instituto Ben-Zvi. 2008.

Amicis, Edmondo de. Morocco its People and Places. Translated by C. Rollin-Tilton. London, Paris \& NewYork: Cassell, Peller, Galpin \& Co, 1882.

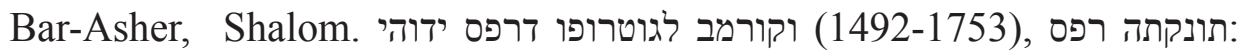

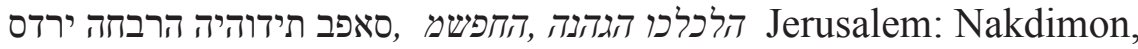
1990.

Bendayan de Bendelac, Alegría. Diccionario del Judeoespañol de los Sefardies del Norte Marruecos. Caracas: Centro de estudios Sefardíes. 1995.

Bendayan de Bendelac, Alegría. Voces Jaquetiescas. Caracas: Asociación Israelita de Venezuela. 1990.

Bendelac, Alegría. Los Nuestros, Sejina, Letuarios, Jaquetía y Fraja. New York: Peter Lang. 1987

Benharroch B., Isaac. Diccionario de Haquetía. Caracas: Centro de Estudios Sefardíes deCaracas. 2004.

Benoliel, Jose. Dialecto Judeo-Hispano - Marroquí o Hakitía. Madrid: Copisteria Varona. 1977.

Bentolila, Yaakov. "La lengua común (coiné) judeo-española entre el Este y el Oeste." En El Presente, Estudios sobre la cultura Judeo-Española del Norte de Marruecos. Editado por Tamar Alexander- Frizer y Yaakov Bentolila, 159-176. Beer Sheva: Centro Gaon, Universidad Ben Gurion del Negev. 2008.

Chetrit, Joseph. "Judeo-Arabic and Judeo-Spanish in Morocco and their Sociolinguistic Interaction." En Readings in the Sociology of Jewish Languages. Edited, Joshua A. Fishman, 261-79. Leiden: E. J. Brill, 1985. 
Cohen, Herzel. רוחש שיש ינבא)Piedras de mármol negro). Tel Aviv: ${ }^{\complement} \mathrm{Am}$ 'oved. 2004.

Díaz-Mas, Paloma. Sephardim, the Jews from Spain. Edited and translated by George K. Zucker. Chicago: The University of Chicago Press, 1992.

Laredo, Abraham. Los orígenes de los judios de Marruecos. Madrid: Hebraica Ediciones, 2007.

Larrea Palacín, Arcadio de. Romances de Tetuán. Recogidos y transcritos. Vol. I. Madrid: I.D.E.A. 1952.

Levy, Solly. El libro de Selomó. Madrid: Hebraica Ediciones, 2008.

Levy, Solly. El segundo libro de Selomó. Barcelona: Tirocinio, 2014.

Ortega, Manuel L. Los hebreos en Marruecos. Madrid: Editorial hispano africana. 1919.

Pimienta, Gladys y Sidney Pimienta. 1860-1883 Libro de actas de la junta selecta de la comunidad hebrea de Tánger. Paris-Jerusalem: Jem Y Erez, 2010.

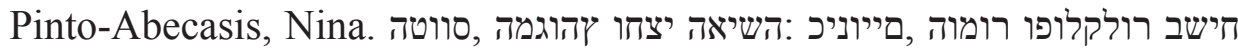
(El pavo el planchadoy la media). Jerusalem: Ben-Zvi institute, 2014. הייתכחה ירבויר.

Séphiha, Haïm Vidal. "Judeo-Spanish, Birth, Death and Re-birth." En Yiddish and Judeo-Spanish, A European Heritage, ed. Nathan Weinstock, Haïm Vidal Séphiha and Anita Barrera-Schoonheere, 23-41. Brussels: European Bureau for Lesser Used Languages, 1997.

Séphiha, Haïm Vidal. "Hablas ibéricas de los sefardíes tras de la expulsión (1942) (hispanohablantes, judeo- hispanohablantes y lusohablantes)."

En Los sefardies de ayer y de hoy. Edited by Richard Ayoun and Haïm Vidal Séphiha. Translated by Tomás Onaindía, 328-338. Madrid: Edaf. 2002.

Sisso Raz, Alicia. "Haketía: Discovering the Other Judeo-Spanish Vernacular,"en Judeo-panish and the Making of a Community. Editado por Bryan Kirschen. New Castle: Cambridge Scholars Publishing. 2015. 113-131.

Vilar, Juan BTA. Tetuán en el resurgimiento judío contemporáneo (18501870). Caracas: Biblioteca Popular Sefardi, 1985.

Zafrani, Haim. Two Thousand Years of Jewish Life in Morocco. Jersey City: KTAV Publishing House, 2005. 


\begin{abstract}
In recent years, there has been a growing interest in Haketía and in the heritage of the community that speaks it. This development could be a favorable indication to what the future may hold.

However, not much has been written in Haketía, and the contemporary writers in this dialect are numbered. One of the contributing factors is the lack, until recently, of an orthographic system. But more critical is the tendency of its speakers to view Haketía as a language of a lower register, whose vocabulary is inadequate to articulate and write substantial thoughts. It has been commonly regarded as a vernacular best suited for commonplace conversations, and the heavily infused jokes, aphorisms, expressions, and curses, amplify this perception. In this article I will explore the dialect and its multifaceted aspects in Haketía.
\end{abstract}

Keywords: Haketia, Judeo-Spanish, Ladino, Morroco, slang.

\title{
Biographical statement
}

ALICIA SISSO RAZ is a cultural activist who promotes the exploration and understanding of Sephardic history and culture. She was born in Morocco, grew up in Israel, and has lived in NY for most of her adult life. Ms. Sisso Raz focuses on research, writing, and consulting on the language and cultural aspects of the Moroccan Sephardim, while archiving their personal testimonies, to be integrated into her work. For this reason, she launched and monitors www.vocesdehaketia.com, which aims to preserve the language and raise awareness of Haketía. Her articles and short stories in Haketía have been featured in various publications around the world, including the archives at the Museum of the Jewish People, Tel Aviv; monthly articles in El Amaneser, Istanbul; translations of two chapters from the second book of Don Quixote, part of the projects Quijote Políglota de El Toboso, Toledo, and Don Quijote Universal, Facultad de Filología, Universidad Complutense, Madrid. Ms. Sisso Raz holds an MA in art history. She served on the Executive Board of the American Sephardi Federation in NY, and has been the Art Services Director at Queens Council on the Arts, NY.

E-mail: alicia@vocesdehaketia.com,monsonego@gmail.com 